\title{
Is Neck Circumference a Marker for Cardiovascular Risk in Obese Adolescents?
}

\author{
Bruno Faria ${ }^{1, *}$, Maria Arlete Meil Schimith Escrivão ${ }^{2}$ and Paulo Cesar Koch Nogueira ${ }^{1}$ \\ ${ }^{1}$ Pediatrics Department - Escola Paulista de Medicina - UNIFESP, Rua Botucatu, 598- Vila clementino, Zip \\ code: 04023-062. São Paulo-SP, Brazil \\ ${ }^{2}$ Nutrology Discipline of the Pediatrics Department - Escola Paulista de Medicina - UNIFESP, Rua \\ Loefgreen, 1647, Vila Clementino, Zip code 04040-032, São Paulo-SP, Brazil
}

\begin{abstract}
Background: Weight excess has become a public health problem worldwide, reaching about 200 million children, of whom 40 to 50 million are obese. Obesity in childhood is associated with increased blood pressure (BP), high triglycerides, low HDL-cholesterol and abnormal glucose metabolism. Visceral fat is a stronger predictor of metabolic dysfunction and cardiovascular risk than total body adiposity. Assessment of neck circumference (NC) is an easy method, which can serve as screening to identify individuals with weight excess. Our study aim was to examine associations between NC with BP values, lipid profile, blood glucose and fasting insulin in obese adolescents and verify the reproducibility of measurements of $\mathrm{NC}$
\end{abstract}

Methods: 82 adolescents aged 10 to 17 years were included in the study, being 43 (22 boys and 21 girls) with obesity and 39 with normal weight ( 20 boys and 19 girls).

Results: Significant associations were observed between NC and BMI, BP, HDL cholesterol, insulin and HOMA-IR. Disagreement between both observers for NC was observed in $5.2 \%$ of the sample, only concerning obese individuals.

Conclusion: Our findings strengthen the knowledge about the potential value of NC as a tool for identifying patients at risk for hypertension, insulin resistance, and obesity. However as with the waist circumference it may be flawed in obese individuals.

Keywords: Neck circumference, obesity, adolescent, cardiovascular diseases, diagnosis.

\section{INTRODUCTION}

Weight excess has become a public health problem worldwide [1] and its prevalence has rapidly increased [2] reaching about 200 million children, of whom 40 to 50 million are considered obese [3]. According to the World Health Organization (WHO) this is one of the most serious public health problems of the 21st century [3]. Weight excess in children and adolescents is related to more severe obesity and increases cardiovascular risk in adulthood [4].

Diagnosis of obesity is usually confirmed by measuring body mass index (BMI) based on WHO curves, according to sex and age [5]. BMI is a good parameter for determining the weight excess, but it does not differentiate subcutaneous fat from visceral fat, which is related to cardiovascular risk $[6,7]$. Data from the US Preventive Services Task Force does not favor conclusive evidence to support the use of BMI as a screening tool for the diagnosis of obesity [8], due to an inability to distinguish between fat mass and lean mass as the major limitation of this index [9]. This is important as the relationship between body fat mass and cardiovascular risk is well established $[10,11]$.

*Address correspondence to this author at the Pediatrics Department, Rua Botucatu, 598- Vila clementino, Zip code: 04023-062, São Paulo-SP, Brazil; Tel: +55 11 55764848; E-mail: brunofaria11@hotmail.com
The distribution of body fat is a stronger predictor of metabolic dysfunction and cardiovascular risk than total body fat. The wide use of waist circumference (WC) is based on its relation with the visceral abdominal fat and its important role in cardiovascular risk evaluation [1215]. However, the seemingly simple measurement of WC entails taking off clothing in addition to technical difficulties such as: a) the location of the midpoint between the last rib and the iliac crest, b) the need to be done on expiration and $c$ ) the potential variation between the pre- and post-prandial state. Consequently, WC measure discrepancies are observed among different examiners [16] and these difficulties are greater in individuals with obesity, the clinical situation in which the measurement is most relevant.

Given the existing difficulties with the measurements available to characterize obesity, it is of great practical importance to use a complementary parameter, which ideally could be carried out more simply, especially in epidemiological studies in which many individuals could be evaluated promptly by different professionals and often in open places.

A method that theoretically fills these requirements is the measurement of NC. This is inexpensive, fast and easily measured and can serve as an

(C) 2016 Lifescience Global 
anthropometric measure to indirectly assess visceral fat [17-20]. The NC is positively correlated with the WC itself, with hypertension, dyslipidemia and insulin resistance, making it a potential predictor of risk for cardiovascular disease [20-24].

Studies on the NC in adults have shown the relationship of it with the metabolic risk indicators, suggesting that it is a potentially important tool for use in clinical practice. The literature on the subject in adolescents showed similar results, but no study has evaluated the reproducibility of this measurement. Hence, we considered that evaluating the association between NC and cardiovascular risk and also the reproducibility of this measurement could be useful in this age group.

\section{OBJECTIVE}

a) To test the association between measurements of NC with blood pressure levels, lipid profile, blood glucose and fasting insulin in obese adolescents;

b) To check the reproducibility of the measurement of NC.

\section{METHODS}

A total of 82 adolescents aged 10 to 17 years were included in the study, being 43 obese (BMI percentile greater than 97 percentile of WHO, 2007) subjects (22 boys and 21 girls) and 39 teenagers (20 boys and 19 girls) BMI lower than $85^{\text {th }}$ percentile. Individuals in the obese group were seen at pediatric nutrology obesity clinic between November 2011 and October 2012. To ensure representation of cardiovascular risk adolescents, we selected those who were obese and either one or more of the following risk factors: hypertension, dyslipidemia, insulin resistance or hyperglycemia. For the control group, teenagers were selected from the pediatric clinic of basic health unit in Pedra Bela city, state of São Paulo, between March 2012 and December 2012.

We only included those who agreed to participate in the study after signing both the consent form by their legal guardians and the assent form by the teenager. Patients with secondary obesity (endocrine diseases, genetic syndromes), deformities in the neck, cervical lymphadenopathy were excluded from the study.

The average from three anthropometric measurements by the same observer was recorded.
One of the two examiners was responsible for both measurements, whereas the second was not the same in the two centers. Weight on a digital scale with accuracy of $0.1 \mathrm{~kg}$, with the teenager without shoes and wearing light clothing was measured. Stature was recorded using a wall fixed stadiometer, with individuals standing erect and barefooted.

WC was measured at the midpoint between the last rib and the upper border of the iliac crest, with patients standing upright and at the end of expiration. The measurement of the NC was carried out at the level of the thyroid cartilage in the horizontal plane of the neck with individuals seated with head erect facing forward [25]. Two examiners assessed the measurement of NC separately three times in order to evaluate its reproducibility.

Blood pressure was measured with aneroid sphygmomanometer, after ten minutes rest in a sitting position with the right arm at heart level. Three measurements were performed, and the average was recorded [26].

Homeostasis model assessment for insulin resistance (HOMA-IR) was calculated by the formula: fasting insulin $(\mu \mathrm{U} / \mathrm{mL}) \times$ fasting glucose $(\mathrm{mmol} / \mathrm{L}) /$ 22.5 , with the cut-off value greater than or equal to 3.43 [27].

The results of blood glucose and fasting insulin, triglycerides, lipid profile were retrospectively analyzed only for obese patients. We used the results from the latest consultation prior to anthropometric measurements (maximum of 3 months).

\section{Statistical Analysis}

Quantitative variables were expressed as mean and standard deviation values, while qualitative variables were expressed as frequencies. Statistical evaluation of results involved comparisons of results between groups (obese versus normal weight), using Student's $t$ test for quantitative variables and the chi-square test in the case of qualitative variables frequency comparisons. In addition, linear regression analyses of variables were performed, in which the measurements of NC and WC were considered as independent variables, while the cardiovascular risk factors (systolic blood pressure, diastolic blood pressure, lipid profile, blood glucose, insulin and HOMA) were considered as outcome variables. Finally, in 77 individuals (38 obese and 39 with normal weight) we evaluated the 
agreement between the measurements of NC by different observers using the Bland-Altman method [28]. The software STATA 13.1 (College Station, TX 77845 USA) was utilized and all tests were two-tailed, being $5 \%$ the limit adopted to reject the null hypothesis $(\alpha<0.05)$.

\section{RESULTS}

There were $22 / 43$ boys in the obese group (51\%), the same proportion observed in normal weight $(\mathrm{n}=$ $20 / 38,51 \%$ ). Age was comparable between the two groups, with a mean of 12.8 years $(S D=2.2)$ among obese patients and 13.6 years $(S D=2.1)$ in normal weight individuals $(p=0.12)$. Just one 10.8 years girl had low height ( $Z$ Score -2.23) and her weight was $48 \mathrm{~kg}$. Blood pressure was significantly different in the two groups, showing higher levels in obese patients. All the comparisons between groups are depicted in Table 1 and the results of linear regression analyses between the NC and cardiovascular risk variables are shown in Table 2.

To better illustrate these data we categorized NC and WC Z Scores of our sample in quartiles. In the eutrophic group, $54 \%$ of the adolescents were in the $1^{\text {st }}$ quartile for NC and only $3 \%$ in the $4^{\text {th }}$ quartile, whereas in the obese group, $2 \%$ were in the $1^{\text {st }}$ quartile and $44 \%$ in the $4^{\text {th }}$ quartile $(p<0.001)$. With regard to WC, $97.5 \%$ of the eutrophic adolescents were in the $1^{\text {st }}$ and $2^{\text {nd }}$ quartiles, while in the obese group, $93 \%$ were in the $3^{\text {rd }}$ and $4^{\text {th }}$ quartile $(p<0.001)$.

The agreement between the measurements of neck circumference between the two examiners was satisfactory, as shown in Figure 1. Four teens surpassed the limits of Bland-Altman graph and three of them were considered severely obese (BMI Z Score of the four were $2.69,3.55,3.65$ and 4,53 ).

\section{DISCUSSION}

The main finding of our study was the association observed between the measurement of NC with: a) BMI, b) systolic and diastolic blood pressure, c) HDL Cholesterol, d) insulin level and e) HOMA. This qualifies the NC to evaluate anthropometry in adolescents, serving as a screening tool for obesity and cardiovascular risks in these individuals.

The association between NC and blood pressure is noteworthy and resulted in the estimation that every 1 $\mathrm{cm}$ increase in NC was associated with a rise of 2.4 $\mathrm{mmHg}$ systolic BP and $1.2 \mathrm{mmHg}$ diastolic BP. Considering that elevated blood pressure is one of the

Table 1: Anthropometric and Metabolic Variable Comparisons between Obese and Eutrophic Groups

\begin{tabular}{|c|c|c|c|c|}
\hline & Total & Obese & Eutrophic & $p$ \\
\hline Weight (Kg) & $61.5(21.2)$ & $75.3(18.6)$ & $46.4(11.2)$ & $<0.001$ \\
\hline Height $(\mathrm{cm})$ & $156.5(11.4)$ & $157.2(11.2)$ & $155.8(11.7)$ & 0.55 \\
\hline Height Z Score & $0.25(1.0)$ & $0.52(1.0)$ & $-0.05(1.0)$ & 0.012 \\
\hline $\mathrm{BMI}\left(\mathrm{Kg} / \mathrm{m}^{2}\right)$ & $24.7(6.9)$ & $30.1(4.9)$ & $18.8(2.3)$ & $<0.001$ \\
\hline BMI ZScore & $1.4(1.6)$ & $2.8(0.6)$ & $-0.2(0.8)$ & $<0.001$ \\
\hline WC $(\mathrm{cm})$ & $78.1(15.7)$ & $90.5(10.5)$ & $64.3(5.9)$ & $<0.001$ \\
\hline $\mathrm{NC}(\mathrm{cm})$ & $32.5(3.6)$ & $34.9(2.9)$ & $30.0(2.4)$ & $<0.001$ \\
\hline NC ZScore & $0.8(1.6)$ & $2.1(1.0)$ & $-0.6(0.8)$ & $<0.001$ \\
\hline Systolic BP (mmHg) & $108(15)$ & $113(15)$ & $103(12)$ & 0.001 \\
\hline Diastolic BP $(\mathrm{mmHg})$ & $68(10)$ & $71(11)$ & $64(8)$ & 0.001 \\
\hline Serum Glucose (mg/dl) & - & $89.4(7.7)$ & - & - \\
\hline Triglycerides (mg/dl) & - & $113.2(57.8)$ & - & - \\
\hline Total Cholesterol (mg/dl) & - & $166.2(26.8)$ & - & - \\
\hline HDL Cholesterol (mg/dl) & - & $42.5(10.1)$ & - & - \\
\hline LDL Cholesterol (mg/dl) & - & $101.8(26.3)$ & - & - \\
\hline Insulin $(\mu \mathrm{U} / \mathrm{ml})$ & - & $15.0(9.7)$ & - & - \\
\hline HOMA & & $3.3(2.2)$ & & \\
\hline
\end{tabular}

BMI=Body Mass Index; WC=Waist Circumference; NC=Neck Circumference. 
Table 2: Association of Neck Circumference and Waist Circumference with Cardiovascular Risk Variables in Obese Adolescents

\begin{tabular}{|c|c|c|c|c|c|}
\hline & & Coefficient (SE) & $95 \% \mathrm{Cl}$ & $\mathbf{R}^{2}$ & $\mathbf{P}$ \\
\hline BMI SDS* $(n=82)$ & $\begin{array}{l}\mathrm{NC} \\
\mathrm{WC}\end{array}$ & $\begin{array}{l}0.32(0.04) \\
0.09(0.01)\end{array}$ & $\begin{array}{c}0.25-0.39 \\
0.08-0.10\end{array}$ & $\begin{array}{l}0.51 \\
0.81\end{array}$ & $\begin{array}{l}<0.001 \\
<0.001\end{array}$ \\
\hline Systolic BP* $(n=82)$ & $\begin{array}{l}\mathrm{NC} \\
\mathrm{WC}\end{array}$ & $\begin{array}{l}2.40(0.40) \\
0.50(0.90)\end{array}$ & $\begin{array}{l}1.60-3.10 \\
0.30-0.70\end{array}$ & $\begin{array}{l}0.34 \\
0.30\end{array}$ & $\begin{array}{l}<0.001 \\
<0.001\end{array}$ \\
\hline Diastolic BP* $(n=82)$ & $\begin{array}{l}\mathrm{NC} \\
\mathrm{WC}\end{array}$ & $\begin{array}{l}1.20(0.30) \\
0.30(0.70)\end{array}$ & $\begin{array}{l}0.70-1.80 \\
0.20-0.40\end{array}$ & $\begin{array}{l}0.19 \\
0.20\end{array}$ & $\begin{array}{l}<0.001 \\
<0.001\end{array}$ \\
\hline Serum Glucose $(n=43)$ & $\begin{array}{l}\mathrm{NC} \\
\mathrm{WC}\end{array}$ & $\begin{array}{l}-0.50(0.40) \\
-0.13(0.11)\end{array}$ & $\begin{array}{l}-1.30-0.30 \\
-0.40-0.10\end{array}$ & $\begin{array}{l}0.04 \\
0.03\end{array}$ & $\begin{array}{l}0.230 \\
0.270\end{array}$ \\
\hline Total Cholesterol $(n=43)$ & $\begin{array}{l}\mathrm{NC} \\
\mathrm{WC}\end{array}$ & $\begin{array}{l}-1.00(1.40) \\
-0.40(0.40)\end{array}$ & $\begin{array}{l}-4.00-1.90 \\
-1.20-0.40\end{array}$ & $\begin{array}{l}0.01 \\
0.03\end{array}$ & $\begin{array}{l}0.470 \\
0.307\end{array}$ \\
\hline HDL-Cholesterol $(n=43)$ & $\begin{array}{l}\mathrm{NC} \\
\mathrm{WC}\end{array}$ & $\begin{array}{l}-1.30(0.50) \\
-0.25(0.15)\end{array}$ & $\begin{array}{l}-2.30-0.30 \\
-0.50-0.04\end{array}$ & $\begin{array}{l}0.14 \\
0.07\end{array}$ & $\begin{array}{l}0.015 \\
0.093\end{array}$ \\
\hline LDL Cholesterol $(n=43)$ & $\begin{array}{l}\mathrm{NC} \\
\mathrm{WC}\end{array}$ & $\begin{array}{l}-0.80(1.40) \\
-0.50(0.40)\end{array}$ & $\begin{array}{l}-3.70-2.10 \\
-1.20-0.30\end{array}$ & $\begin{array}{l}0.01 \\
0.03\end{array}$ & $\begin{array}{l}0.581 \\
0.232\end{array}$ \\
\hline VLDL Cholesterol $(n=43)$ & $\begin{array}{l}\mathrm{NC} \\
\mathrm{WC}\end{array}$ & $\begin{array}{l}0.40(0.40) \\
0.20(0.10)\end{array}$ & $\begin{array}{c}-0.40-1.20 \\
-0.003-0.40\end{array}$ & $\begin{array}{l}0.02 \\
0.10\end{array}$ & $\begin{array}{l}0.330 \\
0.053\end{array}$ \\
\hline Insulin $(n=43)$ & $\begin{array}{l}\mathrm{NC} \\
\mathrm{WC}\end{array}$ & $\begin{array}{l}1.30(0.50) \\
0.50(0.10)\end{array}$ & $\begin{array}{l}0.30-2.30 \\
0.20-0.70\end{array}$ & $\begin{array}{l}0.15 \\
0.25\end{array}$ & $\begin{array}{l}0.011 \\
0.001\end{array}$ \\
\hline Homa $(n=43)$ & $\begin{array}{l}\mathrm{NC} \\
\mathrm{WC}\end{array}$ & $\begin{array}{l}0.30(0.10) \\
0.10(0.03)\end{array}$ & $\begin{array}{l}0.04-0.48 \\
0.03-0.15\end{array}$ & $\begin{array}{l}0.13 \\
0.20\end{array}$ & $\begin{array}{l}0.020 \\
0.003\end{array}$ \\
\hline Triglycerides $(n=43)$ & $\begin{array}{l}\mathrm{NC} \\
\mathrm{WC}\end{array}$ & $\begin{array}{l}3.00(3.00) \\
0.90(0.80)\end{array}$ & $\begin{array}{l}-3.30-9.20 \\
-0.80-2.60\end{array}$ & $\begin{array}{l}0.02 \\
0.03\end{array}$ & $\begin{array}{l}0.345 \\
0.277\end{array}$ \\
\hline
\end{tabular}

most established cardiovascular risk factors [29], this association seemed to be the most significant clinically.

In a previously published study the NC was positively correlated with the WC, height, weight, age and BMI [25]. Unfortunately, in that study only BMI was evaluated as a surrogate for cardiovascular risk, whereas in our sample we extended these associations to different risk factors, such as lipid profile, insulin and blood pressure. Once again, the measurement of NC appeared potentially useful as a risk identifier.

In another study including adult patients [17], the NC was positively correlated with HOMA and visceral fat measured by CT of the abdomen. In addition, there was no WC correlation with visceral fat in the same study, thus strengthening the potential importance of $\mathrm{NC}$ as a valid anthropometric measurement to identify individuals at risk for cardiovascular disease.

In our sample both NC and WC were associated with similar risk factors. Therefore, according to our data, we cannot affirm that the NC is more valid than the measurement of the WC in identifying the cardiovascular risks in adolescents. However, in the present data only NC (not WC) was associated with HDL.

In another study involving 1053 adults in Brazil, positive correlations were identified between the NC with triglycerides, fasting glucose, insulin, HOMA and visceral fat in both sexes [22]. These findings corroborate our results supporting the role of NC measurement as a cardiovascular risk identifier. However in contrast to the study in Brazilian adults, we found no significant association with serum glucose and triglycerides and it is possible that this difference is due to the small size of our sample compared to the study in adults. Additionally, in our study we were able to confirm a positive correlation between NC and WC, as evidenced in previous studies [16, 19, 20,30].

In a recent study conducted in Brazil involving 2794 children and adolescents aged 6-19 years the authors confirmed the correlation of NC measurement with the WC and BMI. Moreover they determined cut-off points for NC [18]. We then calculated the NC Z scores of the individuals in our sample using the figures reported by 


\section{Agreement between Observer 1 and Observer 2}

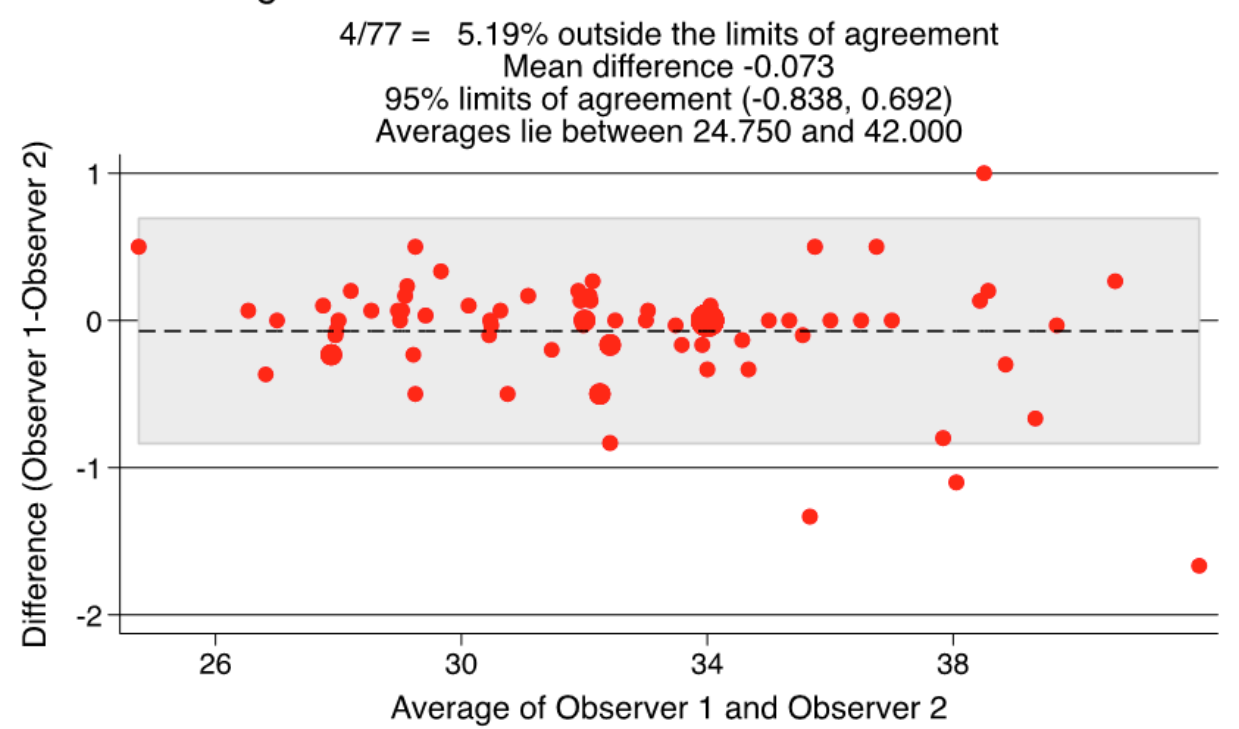

Figure 1: Graphical representation of agreement of neck circumference measurements assessed by two observers.

Coutinho and colleagues [18]. In the obese group from our sample the Z score for $\mathrm{NC}$ was $2.08(95 \% \mathrm{Cl}=$ 1.76 to 2.40 ), whereas in the control group it was -0.55 $(95 \% \mathrm{Cl}-0,30$ to -0.80$)$. Also the NC Z scores were significantly associated with serum insulin (increase of 1SDS in the $\mathrm{z}$ score of NC was associated with 4.5 times higher serum insulin) and blood pressure measurements (1SDS increase in NC Z score was associated with $3.4 \mathrm{mmHg}$ and $2.2 \mathrm{mmHg}$ elevation in systolic and diastolic respectively). The fact that the values of NC Z scores in our sample had a consistency with the values described by Coutinho and colleagues [18] suggests that the measurement of NC can be useful in clinical practice as a cardiovascular risk indicator and it include the possibility of using it in different age groups of the pediatric population.

In other research involving children and adolescents aged 5-18 years [23] similar correlations of NC with all risk factors were observed, with the exception of glucose in both sexes and CT in pubescent girls. The author suggested that these differences occurred due to hormones levels, but could not establish a conclusive relationship. Unlike Kurtoglu $S$ et al. [23], the patients in our study were not classified according to pubertal stage because our focus was on measuring NC as a useful anthropometric toll on a daily basis, independently of pubertal stage.

More recently Da Silva et al. [31] reported on a very similar study to our work with a larger number of individuals in the same age group. In this study the authors detected a positive correlation of NC with insulin and HOMA-IR, except in prepubescent males. Similarly to our study, they also observed a positive correlation between the measurement of NC with systolic and diastolic blood pressure, except among prepubertal girls. They also identified the negative association of NC with HDL cholesterol, but only in pubescent individuals. In all essential aspects our work confirms and extends their findings in a smaller sample. We believe that this reinforces the central hypotheses of this study. One of our major limitations is not having the pubertal stages of the patients at the moment of the study measurements. At the study onset we considered reporting the self-assessment of Tanner stage by the patients but this could result in errors. Therefore we recognize that the pubertal stage should have been evaluated considering the wide age range (10-17 years) selected for this study and the interpretation of our results should be moderated by the lack of this important information

Our work has limitations due to the small number of patients involved in the study. In addition, the individuals from the control group were admitted from a different center and their blood was not collected for laboratory analyses, as in the obese patients. Finally, the cross-sectional study design that we adopted was our biggest limitation, since causal associations cannot be tested with this type of clinical study. However, we believe that our research has interest because new hypotheses may arise from our findings and they can contribute to more robust future projects to investigate these hypotheses. 
In conclusion, the findings of our work strengthens the current knowledge about the use of the NC as a potentially important tool to identify individuals at risk for hypertension, insulin resistance and as an additional anthropometric measurement to the WC. We believe that this measurement can play an important role in cardiovascular risk screening in children and adolescents, particularly in subgroups in which the WC measure is problematic such as patients in wheelchairs, undergoing abdominal surgery, solid organs transplantation and ascites, for example. An innovative aspect of our findings is that we introduced the analysis of concordance between measurements, which showed a reasonable agreement between the observers of NC in our sample. However if we take into account that there were 4 discordant measures between the two observers (5.9\%) and that these four individuals belonged to the obese group, it is clear that in 4 out of 38 subjects (10.5\%) the observations were not concordant. This may be either due to specific difficulties in the obese subgroup such as the presence of a hump, or due to the presence of Adam's apple in older male adolescents, potentially leading to measurement inaccuracies. We also performed the analysis of concordance of WC measurements on the same 77 subjects (data not shown). The WC concordance analysis revealed $3 / 77$ values outside the limits of agreement, all with obesity, suggesting that the degree of agreement and difficulties seen in relation to WC were similar to that which occurred with the NC. These facts should be taken into account, since measurement of NC is a relatively simple method, it may have problems of reliability, particularly in obese individuals. Notwithstanding this limitation, measurement of NC is an inexpensive anthropometric measurement, easy to perform and does not require removal of clothing, which usually embarrasses obese individuals.

\section{ACKNOWLEDGMENTS}

I thank my coaches for patience and availability.

\section{AUTHOR DISCLOSURE STATEMENT}

No competing financial interests exist.

\section{REFERENCES}

[1] Ogden CL, Carroll MD, Flegal KM. High body mass index for age among US children and adolescents, 2003-2006. JAMA 2008; 299(20): 2401-5. http://dx.doi.org/10.1001/jama.299.20.2401

[2] Obesity: preventing and managing the global epidemic. Report of a WHO consultation. World Health Organ Tech Rep Ser 2000; 894: i-xii, 1-253.
Bhatia J. Editorial--the global epidemic of obesity. Ann Nutr Metab 2014; 64 Suppl 1: 5-6.

\section{http://dx.doi.org/10.1159/000362678}

[4] Daniels SR, Jacobson MS, McCrindle BW, Eckel RH, Sanner BM. American Heart Association Childhood Obesity Research Summit Report. Circulation 2009; 119(15): e489-517. http://dx.doi.org/10.1161/CIRCULATIONAHA.109.192216

[5] Quak SH, Furnes R, Lavine J, Baur LA, Group OW. Obesity in children and adolescents. J Pediatr Gastroenterol Nutr 2008; 47(2): 254-9.

\section{http://dx.doi.org/10.1097/MPG.0b013e318181b2cd}

[6] Steinberger J, Daniels SR, Eckel RH, Hayman L, Lustig RH, McCrindle B, et al. Progress and challenges in metabolic syndrome in children and adolescents: a scientific statement from the American Heart Association Atherosclerosis, Hypertension, and Obesity in the Young Committee of the Council on Cardiovascular Disease in the Young; Council on Cardiovascular Nursing; and Council on Nutrition, Physical Activity, and Metabolism. Circulation 2009; 119(4): 628-47. http://dx.doi.org/10.1161/CIRCULATIONAHA.108.191394

[7] Speiser PW, Rudolf MC, Anhalt H, Camacho-Hubner C, Chiarelli F, Eliakim A, et al. Childhood obesity. J Clin Endocrinol Metab 2005; 90(3): 1871-87. http://dx.doi.org/10.1210/jc.2004-1389

[8] Whitlock EP, Williams SB, Gold R, Smith PR, Shipman SA. Screening and interventions for childhood overweight: a summary of evidence for the US Preventive Services Task Force. Pediatrics 2005; 116(1): e125-44. http://dx.doi.org/10.1542/peds.2005-0242

[9] Phan TL, Maresca MM, Hossain J, Datto GA. Does body mass index accurately reflect body fat? A comparison of anthropometric measures in the longitudinal assessment of fat mass. Clin Pediatr (Phila) 2012; 51(7): 671-7.

http://dx.doi.org/10.1177/0009922812440838

[10] Casazza K, Dulin-Keita A, Gower BA, Fernandez JR. Intrabdominal fat is related to metabolic risk factors in Hispanic Americans, African Americans and in girls. Acta Paediatr 2009; 98(12): 1965-71. http://dx.doi.org/10.1111/j.1651-2227.2009.01474.x

[11] Lovejoy JC, de la Bretonne JA, Klemperer M, Tulley R. Abdominal fat distribution and metabolic risk factors: effects of race. Metabolism. 1996; 45(9): 1119-24.

http://dx.doi.org/10.1016/S0026-0495(96)90011-6

[12] Preis SR, Massaro JM, Robins SJ, Hoffmann U, Vasan RS, Irlbeck $\mathrm{T}$, et al. Abdominal subcutaneous and visceral adipose tissue and insulin resistance in the Framingham heart study. Obesity (Silver Spring) 2010; 18(11): 2191-8. http://dx.doi.org/10.1038/oby.2010.59

[13] de Onis M, Habicht JP. Anthropometric reference data for international use: recommendations from a World Health Organization Expert Committee. Am J Clin Nutr. 1996; 64(4): 650-8.

[14] Pouliot MC, Després JP, Lemieux S, Moorjani S, Bouchard $\mathrm{C}$, Tremblay A, et al. Waist circumference and abdominal sagittal diameter: best simple anthropometric indexes of abdominal visceral adipose tissue accumulation and related cardiovascular risk in men and women. Am J Cardiol. 1994; 73(7): 460-8. http://dx.doi.org/10.1016/0002-9149(94)90676-9

[15] Klein S, Allison DB, Heymsfield SB, Kelley DE, Leibel RL, Nonas $\mathrm{C}$, et al. Waist Circumference and Cardiometabolic Risk: a Consensus Statement from Shaping America's Health: Association for Weight Management and Obesity Prevention; NAASO, the Obesity Society; the American Society for Nutrition; and the American Diabetes Association. Obesity (Silver Spring) 2007; 15(5): 1061-7. http://dx.doi.org/10.1038/oby.2007.632

[16] Hatipoglu N, Mazicioglu MM, Kurtoglu S, Kendirci M. Neck circumference: an additional tool of screening overweight and obesity in childhood. Eur J Pediatr 2010; 169(6): 733-9. http://dx.doi.org/10.1007/s00431-009-1104-z 
[17] Yang L, Samarasinghe YP, Kane P, Amiel SA, Aylwin SJ. Visceral adiposity is closely correlated with neck circumference and represents a significant indicator of insulin resistance in WHO grade III obesity. Clin Endocrinol (Oxf) 2010; 73(2): 197-200.

[18] Coutinho CA, Longui CA, Monte O, Conde W, Kochi C. Measurement of neck circumference and its correlation with body composition in a sample of students in São Paulo, Brazil. Horm Res Paediatr 2014; 82(3): 179-86. http://dx.doi.org/10.1159/000364823

[19] Katz SL, Vaccani JP, Clarke J, Hoey L, Colley RC, Barrowman NJ. Creation of a reference dataset of neck sizes in children: standardizing a potential new tool for prediction of obesity-associated diseases? BMC Pediatr 2014; 14: 159. http://dx.doi.org/10.1186/1471-2431-14-159

[20] Arnold TJ, Schweitzer A, Hoffman HJ, Onyewu C, Hurtado $\mathrm{ME}$, Hoffman EP, et al. Neck and waist circumference biomarkers of cardiovascular risk in a cohort of predominantly African-American college students: a preliminary study. J Acad Nutr Diet 2014; 114(1): 107-16. http://dx.doi.org/10.1016/.j.jand.2013.07.005

[21] Laakso $M$, Matilainen $V$, Keinänen-Kiukaanniemi $S$. Association of neck circumference with insulin resistancerelated factors. Int J Obes Relat Metab Disord 2002; 26(6): 873-5.

[22] Stabe C, Vasques AC, Lima MM, Tambascia MA, Pareja JC, Yamanaka $A$, et al. Neck circumference as a simple tool for identifying the metabolic syndrome and insulin resistance: results from the Brazilian Metabolic Syndrome Study. Clin Endocrinol (Oxf) 2013; 78(6): 874-81. http://dx.doi.org/10.1111/j.1365-2265.2012.04487.x

[23] Kurtoglu S, Hatipoglu N, Mazicioglu MM, Kondolot M. Neck circumference as a novel parameter to determine metabolic risk factors in obese children. Eur J Clin Invest 2012; 42(6): 623-30. http://dx.doi.org/10.1111/j.1365-2362.2011.02627.x

[24] Nafiu OO, Zepeda A, Curcio C, Prasad Y. Association of neck circumference and obesity status with elevated blood pressure in children. J Hum Hypertens 2014; 28(4): 263-8. http://dx.doi.org/10.1038/jhh.2013.93
[25] Nafiu OO, Burke C, Lee J, Voepel-Lewis T, Malviya S, Tremper KK. Neck circumference as a screening measure for identifying children with high body mass index. Pediatrics 2010; 126(2): e306-10.

[26] Adolescents NHBPEPWGoHBPiCa. The fourth report on the diagnosis, evaluation, and treatment of high blood pressure in children and adolescents. Pediatrics 2004; 114(2 Suppl 4th Report): 555-76.

[27] Matthews DR, Hosker JP, Rudenski AS, Naylor BA, Treacher DF, Turner RC. Homeostasis model assessment: insulin resistance and beta-cell function from fasting plasma glucose and insulin concentrations in man. Diabetologia 1985; 28(7): 412-9.

http://dx.doi.org/10.1007/BF00280883

[28] Sedgwick P. Limits of agreement (Bland-Altman method). BMJ 2013; 346: f1630.

[29] Schwartz B, Jacobs DR, Moran A, Steinberger J, Hong CP Sinaiko AR. Measurement of insulin sensitivity in children: comparison between the euglycemic-hyperinsulinemic clamp and surrogate measures. Diabetes Care 2008; 31(4): 783-8. http://dx.doi.org/10.2337/dc07-1376

[30] Onat A, Hergenç G, Yüksel H, Can G, Ayhan E, Kaya Z, et al. Neck circumference as a measure of central obesity: associations with metabolic syndrome and obstructive sleep apnea syndrome beyond waist circumference. Clin Nutr 2009; 28(1): 46-51. http://dx.doi.org/10.1016/j.clnu.2008.10.006

[31] da Silva CeC, Zambon MP, Vasques AC, Rodrigues AM, Camilo DF, Antonio M, et al. Neck circumference as a new anthropometric indicator for prediction of insulin resistance and components of metabolic syndrome in adolescents: Brazilian Metabolic Syndrome Study. Rev Paul Pediatr 2014; 32(2): 221-9. http://dx.doi.org/10.1590/0103-0582201432210713 